\title{
Dynamic CRM based Knowledge Management for Government's Role
}

\author{
V. Vijayalakshmi \\ Assistant Professor of \\ Computer Science \\ Government Arts College \\ Ariyalur, Tamilnadu, India
}

\author{
P. Sudhakar \\ Associate Professor of \\ Computer Science \\ M.Kumarasamy College \\ Engineering \\ Karur, Tamilnadu, India
}

\author{
A. Pethalakshmi \\ Associate Professor of \\ Computer Science \\ MVM Government Arts College \\ Dindigul, TamilNadu,
}

\begin{abstract}
Customer relationship management (CRM) has become a strategic initiative aimed at getting, growing, and retaining the right customers. A great amount of numeric data and even more soft information are available about customers. In this paper we analyze the relative importance of factors and the priority of the schemes by constructing the CRM hierarchy model for Small and Medium Enterprises. Under the backgrounds of the transmission of the government's role and functions, on the basis of Customer Relationship Management (CRM), we stress on analyzing the theory and principle to design the e-government facing public service. We propose overall framework to integrate the traditional customer relationship management (CRM) functionalities with the management and application of the customer-related knowledge, particularly in the context of marketing decisions. In this paper, we present an integrated framework for CRM through the application of knowledge management technology. The framework can be the basis for enhancing CRM development. With the help of CRM idea, government may better meet the public demand, improve the relationship between government and the public, improve government efficiency, and promote the social stability and harmony. Eventually, some proposals of application of CRM in egovernment are put forward.
\end{abstract}

\section{Keywords}

Customer relationship management, Web mining, egovernment, customer-centered solution, knowledge management, Interactive response mechanism.

\section{INTRODUCTION}

Today, CRM has become a strategic initiative aimed at getting, growing, and retaining the right customers, which leads to long-term profitability. "Every company needs to apply Customer Relationship Management (CRM) in the broad sense of the word. Large scale enterprises tend to CRM self operating; many small and medium enterprises follow this self mode. However, the reason of lacking enough resources and some

restrictive factors such as the complexity of CRM may result CRM self-operating in low efficiency. In fact, the operation mode is an important factor that can influence the efficiency of CRM. So it is significant for small and medium scale enterprises to choose an appropriate CRM operation mode. Current e-government research focuses on improving efficiency and increasing performance within public administration. But e-government is definitely more than just redesigning citizen services and using state-of-the-art information technology. However, the introduction of internet-enabled or internet-architected solutions of themselves will only achieve so much. There is a widespread consensus that public services in the Western democracies are in need of improvement [5][6].

The e-government official website is at the core position, and plays a key, direct and unique role. At present, the overall development of Indian government websites is extremely unbalanced; awareness of the public service also hasn't reached the correct position [7].

A successful implementation of e-government services requires a coordinated development of their internal reorganization and their external relations with customers. To provide the benefits of such transaction services, a customercentered solution is necessary. Web usage mining has become a popular research area, as a huge amount of data is available online. These data can be used for several purposes, such as web personalization, web structure enhancement, web navigation prediction etc [4]. A knowledge discovery process executed on a web log database is similar to that of a traditional database regarding the main steps of the process. However, there is one key step in web log mining that does not exist in the traditional process.

The main purpose of this paper is to explore the evolution, achievements and succeeding trends of different education services, with the theoretical background of e-Government, $\mathrm{CRM}$, and knowledge management (KM). The target population is citizens who have experienced with browsing and searching for the information in e-government web portals. Using Partial Least Squares approach, a highly statistically significant goodness-of-fit is found for the model. The findings indicate that perceived usefulness, perceived ease of use, perceived security and perceived risk, directly enhance the citizen trust in e-Government.

\section{RELATED WORK}

Relationship between the government and the public is also known as the officials and the public relations or cadre-mass relations. As the name suggests, it refers to the relationship between the government and the people or the relationship between officials and ordinary people. So relationship between the relationships since reform and opening in order to improve the relationship between the government and the public, For example, strengthening the construction of people's and increasing administrative transparency, opening government affairs hearing system reducing administrative examination and approval, etc.

There are many differences between e-government and the traditional government, and the main difference is affair operating process and the supporting techniques. The approach of traditional government centered on the functions of various government departments [1]. But e-government takes society's demand as the center, taking "The government is to provide services" as the starting point, in order to help the enterprises, the public, the social organizations and so on 
fast and efficiently resolve various matters, and coordinate kinds of relations. For thousands of years, "compassionate", "ask for suggestions from the people" have always been some sorts of ancient ideas of enlightened rulers, but also the good will of the world people. However, in this great country, there is always certain distance which does not close up between the government and the people. E-government's construction makes the distance to produce quietly a historic change [2][3]. The paper firstly reviews some correlative theories such as public service quality management, interaction quality and the degree of satisfaction etc. Secondly based on these reviews and the practices of the government service, this paper sets a dimension of interaction quality and then builds a model of relationship between interaction quality and public satisfaction, trying to find out what and how much the dimension of interaction quality would impact public satisfaction [7][8]. Therefore, we must stick to public-oriented in the e-government construction, integrate modern information technology to management of the government, and enhance the public and availability of governmental information, establish the interactive response mechanism between the government and the public, and achieve administrative processes to reconstruction.

\subsection{E-government relationship between the government and the Public}

E-government's construction makes the distance to produce quietly a historic change. This research idea that egovernment is the most important and most feasible solution to improve the current relationship between the government and the public which is not satisfying in the current stage. The role of e-government to improve relationship between the government and the public shows in the following aspects: Firstly, e-government can improve both the administrative efficiency of government and the public's satisfaction on the government. Effective administration is the requirement from modern market economy for the government. In the traditional administrative system, the government institution has a bloated size, and the public financial has become the "feeding budge" which makes the financial burden of state heavily.

Traditional government management usually adopts the way of holding meeting to analyse, progressively delivered to the rooted organization and reported to the upper ones. Thus, the government's capacity and efficiency is low. These issues affect the relationship development between the government and the public healthily.

Secondly, e-government provides the reliable support for scientific decision-making and meets the public demand about government services. Under the traditional government, too much power is concentrated in the individual leaders, bureaucracy is the trend, and that the individual make the decisions on major issues, so that lower-ranking officers can not accurately and timely communicate with the upperranking ones. The result will inevitably lead to government information collection and processing system un-through or failed [9]. All the information needed for decision-making can not be promptly and accurately transmitted to the government decision-making system, and incomplete, incorrect and the delayed information makes the decision-making fail. With the construction of facilities maturing in e-government basis and various applications of information putting into use, egovernment has improved the government's ability to receive and process information efficiency, and can obtain from multi-aspect and multi-channel and evaluate information.
Public political participation is an indicator, which measures whether a national government administrative model is effective or not. Under the traditional government, the government's low level of accessibility is one of the reasons for causing deteriorated relations between the government and the people. The channel that accessing to government information is single the cost of that is expensive, and it is subjected to quality and the levels of a small number of government staff.

The public is difficult to access to government information, and the government also does not understand the public's demand, so it is hard for government to solve the practical difficulties of the public effectively out of the public interest. In this case, it is inevitable that the relations between the government and the public estranges. The proportion of public political participation is extremely low, interactive sessions of the government and the public is detached, let alone monitoring the government. Lacking of supervision and regulation, then, the abuse and corruption of power become difficult to avoid

\section{IMPLEMENTATION CRM FRAMEWORK 3.1 Interaction management}

This includes the full range of multi-channel call management functionality now available from CRM vendors. Applications to support traditional face-to-face human interactions are included as are telephone-based call centres and contact centres which also support new channels such as e-mail and other internet-based methods. This category also includes providing the infrastructure for e-service websites enabling self-service facilities and using knowledge tools as supporting technologies. It also requires management information to monitor interaction channel performance and some limited analytics.

We analyse the relative importance of factors and the priority of the schemes by constructing the CRM hierarchy model for Small and Medium Enterprises. Under the backgrounds of the transmission of the government's role and functions, on the basis of Customer Relationship Management (CRM), we stress on analysing the theory and principle to design the egovernment facing public service. We propose overall framework to integrate the traditional customer relationship management (CRM) functionalities with the management and application of the customer-related knowledge, particularly in the context of marketing decisions. In this paper, we present an integrated framework for CRM through the application of knowledge management technology. The framework can be the basis for enhancing CRM development. 


\subsection{Information \& transaction management}

In contrast to interaction management, which is about providing the infrastructure for communicating with the public, these areas of functionality focus on the tools necessary to deliver the relevant information or service. They include content management facilities for deployment internally (e.g. as support for front-line service delivery staff) or externally. They also include commercial functionality for traditional sales or e-commerce applications as well as specialist service applications including revenue collection. To enable cost effective delivery of information or services, integration to back-office financial or business applications and workflow is key to this functionality area.

\subsection{Scheduling management}

Where resources have to be deployed in order to fulfil service obligations, and where the customer's involvement requires a dialogue, this needs scheduling functionality such as is available in Field Service management. Tools to match skills or materials with requirements and optimisation modules to improve productivity are essentially back-office applications, but where they involve interactions with the customer - either to elicit or provide information, or to make, confirm, change or follow-up appointments - these form part of the CRM functionality set.

\subsection{Citizenship management}

A range of specialised applications addressing the relationship between public bodies and the general public, businesses or voluntary bodies which are exercising their civic rights. This therefore covers the publication of proceedings of decisionmaking or consultative bodies including agendas, minutes and relevant papers. It also covers access to and records of the activities of elected or appointed people serving the electorate or various constituencies of interest, along with contact options to encourage interaction over matters of public policy. This category also includes emerging elements of edemocracy in providing functionality to enable electors to vote, be polled or consulted on selected issues, and generally participate in the democratic process. Determining the most likely and most useful returns for each part of the public sector is emerging as an important priority.

E-government makes full use of internet, virtual office, email and remote connection session, etc. It overcomes the travel of the paperwork and documents, reduces man-made disturbances which used to be and increases the ability of government receiving and processing information. At the same time, as a result, the scale of government is being minimized gradually and the expenditure is reduced accordingly which promotes capacity and efficiency of government directly, increases public satisfaction with the government, and achieves the positive interaction and development between the government and the public. According to the subject of e-government and the relationship between the government and the public

Better understanding of how to apply CRM and of the challenges involved in its implementation. The report identifies six main areas of challenge and describes them in detail:-

\section{- Organisational issues}

- The need for a culture change

- Measuring and improving performance

- Learning how to buy CRM

- The privacy problem

- Taking decisions in a dynamic environment
Our research how to reach the good mechanism in the field of e-government between the government and the public is very important to the success of e-government. For the government, it's collection of distributed information from the public, and for the public, its network participation

The construction of e-government must raise awareness that putting heart and soul into serving the public, and the capacity for the public service will be improved significantly. From the rapid development and high levels of e-government in some countries, based on public demand, establishment of a "results oriented" mechanism is the key to success of e-government affairs.

\subsection{Building public-oriented interactive response mechanism}

The way how to reach the good mechanism in the field of egovernment between the government and the public is very important to the success of e-government. For the government, it's collection of distributed information from the public, and for the public, it's network participation. In order to achieve the high effective public participation, an unobstructed channel must be provided, it also needs to organize scattered views and to show the spirit that "of the people by the people for the people" as the "public-oriented " spirit at all aspects. The construction of e-government must raise awareness that putting heart and soul into serving the public, and the capacity for the public service will be improved significantly. From the rapid development and high levels of e-government in some countries, based on public demand, establishment of a "results oriented" mechanism is the key to success of e-government affairs.

Therefore, we must stick to public-oriented in the egovernment construction, integrate modern information technology to management of the government, enhance the publicness and availability of governmental information, establish the interactive response mechanism between the government and the public, and achieve administrative processes to reconstruction. In order for people to participate, phone, fax, letters, and other sources also should be into unified e-government areas except for Internet. Only is public service the pivot and the interactive response mechanism established comprehensively, can the numerous contradictions and conflicts between the government and the public in the egovernment construction be solved effectively, can the support of the public and enterprises be gained indeed.

Whether the e-government applications can realize the interaction, whether the effectiveness of public services can achieve, is to see whether it is fully used by the public, which requires the public to have the basic ability to apply egovernment.

Therefore, government needs to step up training efforts on egovernment applications for the public and enterprises, in particular to pay attention to less developed areas, and to enhance the ability of e-government's universal service, which encourages positive effects of public participation. In addition, cadres and civil servants should also attend in training on knowledge and application skills of e-government and working methods and ability with multichannel, multilevel forms in the network environment. In the meanwhile, leading cadres should strengthen their informationized awareness. In short, we should make full use of television, radio, newspapers, internet and other publicity media, strengthen the publicity on the e-government knowledge and policy combine promote education with science popularization, let the role of public opinion further play, and strive to create a good atmosphere of e-government construction. 
The development of e-government perfects the relationship between the government and the public efficiently, improves the public enthusiasm of political participation, and has realized the information being shared between the government and the public. Even though, in recent years, the domestic e-government has being developed with a rapid pace, there are still lots of problems in its primary stage. Based on the purpose of improving the relationship between the government and the public, under the construction of egovernment, , the domestic government ought to dedicate to build the public-oriented interaction mechanism from now on; based on the official website, integrating the government information resource; enforcing the capacity of the egovernment application.

Requirements include management's CRM goals and direction, business departments' existing and desired CRM process and functions, and IT users' technological requirements.

\subsection{Strategy and process}

Because the project must be conducted on the basis of a clear CRM strategy and process, Management requirements regarding CRM goals and direction influence CRM strategy without a clear CRM strategy, the project team can't design effective CRM processes. Fig 1.0 defines Dynamic CRM strategy guides CRM process development Users' detailed requirements complete the CRM process by defining necessary process and functional issues. Therefore, Requirements from users also influence CRM process development.

\section{Government-specific citizen interaction systems}

We developed as citizen request management systems to modernize operations of local government call centres and face-to-face contact centres.

They then evolved to manage other interaction channels and to provide reporting capabilities.

Organizational commitment refers to the company's supporting activities and factors for target system development.

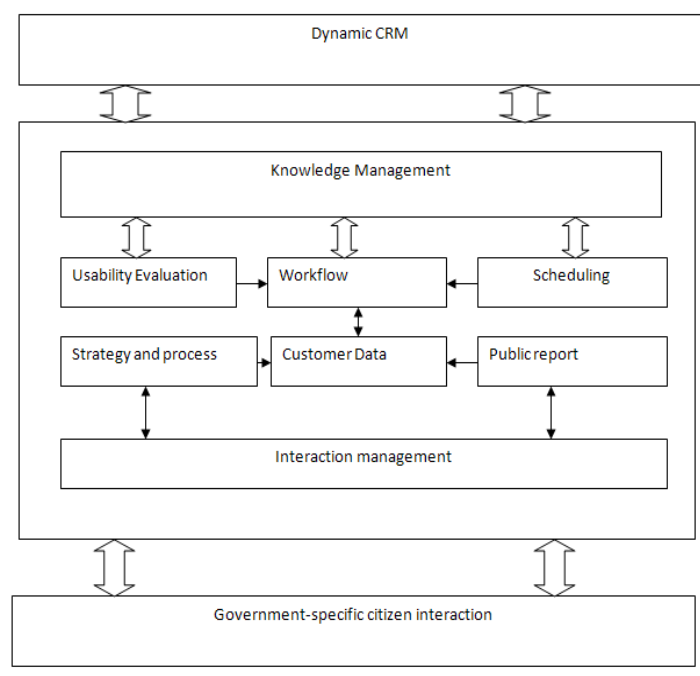

Fig 1: Overall Architecture Dynamic CRM
- $\quad$ Project management includes the project team and managing activities.

- $\quad$ Strategy and process factors express the target IS's strategic direction and business and functional processes

- Technology implies system design and realization activities.

- Consequences refer to the results of system development.

\section{CONCLUSION}

$\mathrm{CRM}$ is helping public sector agencies successfully achieve a reputation change from being bureaucratic, slow moving or unresponsive to being citizen centric and helpful. Researching the connection between e-government and the relationship between the government and the public is a subject of great practical significance. To resolve the problems confronted to the current government and the public relations, e-government is a particularly effective tool and means.

Based on the purpose of improving the relationship between the government and the public, under the construction of egovernment, the domestic government ought to dedicate to build the public-oriented interaction mechanism from now on; based on the official website, integrating the government information resource; enforcing the capacity of the egovernment application

The development of e-government perfects the relationship between the government and the public efficiently, improves the public enthusiasm of political participation, and has realized the information being shared between the government and the public. In this paper, we present an integrated framework for CRM through the application of knowledge management technology. The framework can be the basis for enhancing CRM development.

We developed as citizen request management systems to modernize operations of local government call centers and face-to-face contact centers. However, the research demonstrated that the usability in e-government sites can be evaluated using the specific evaluation method called Dynamic CRM based knowledge Management for Government's Role. Further, taking into account the results from similar research, it was possible to establish a set of recurrent usability problems

\section{REFERENCES}

[1] Du Zhizhou, Wang Yukai , "The development trend of government's good governance under e government---Based on the perspective of interaction between the government and the public", New Vision, no. 2, Apr. 2009, pp. 45-47.

[2] Kang Yijian, "Establishing the service-oriented interactive government in e-government environment ", Journal of the Party School of CPC Leshan, Vol. 11, no. 3, Jul. 2009, pp. 71-72.

[3] O. Etzioni, M.J. Cafarella, D. Downey, A. M. Popescu, et al., Unsupervised Named-Entity Extraction From The Web: An Experimental Study. Artificial Intelligence, 165(1):91-134.2005

[4] Suchanek, F. M., Kasneci, G., \& Weikum, G. Yago: A core of semantic knowledge - unifying WordNet and Wikipedia. WWW07. 
[5] M. Pasca, D. Lin, J. Bigham, A. Lifchits and A. Jain Organizing and Searching The World Wide Web of Facts - Step One: the One-Milliion Fact Extraction Challenge. AAAI06, (pp. 1400-1405). 2006.

[6] R. Bose, "Customer relationships management: key components for IT success", Industrial Management\& Data Systems, 102/2, 89-97, 2002.

[7] Di Maio, Andrea. "Five Key Trends That Will Influence Government IT Strategies for the Next Decade." 19 February 2010. Gartner Inc. 17 May 2011.
[8] Chhabra, Susheel and Kumar Muneesh. Integrating EBusiness Models for Government Solutions: CitizenCentric Service Oriented Methodologies and Processes. Hershey: Information Science Reference, 2009.

[9] F. Pontico, M Winckler, and Q. Limbourg, "Organizing User Interface Patterns for e-Government Applications", Engineering Interactive Systems: EIS 2007

[10] Joint Working Conferences, Springer-Verlag, Salamanca, Spain, March, 2007. 